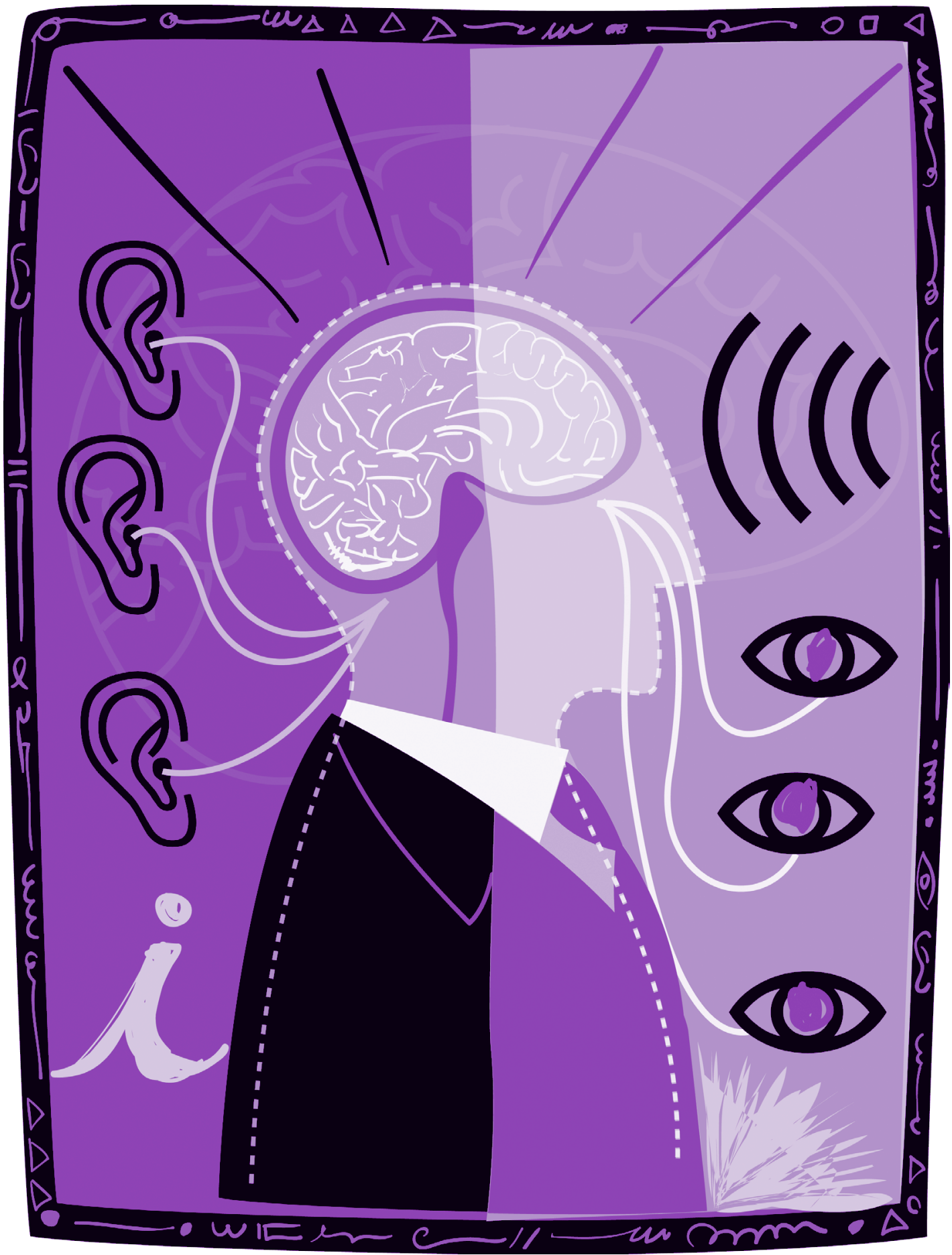




\section{A Comunicação e a tangibilidade de sua avaliação}

Mitsuru Yanaze

- Livre Docente e Doutor em Ciências da Comunicação pela ECA-USP

- Professor de Pós-Graduação e Graduação da ECA-USP

- Professor convidado da Aberje - Associação Brasileira de Comunicação Empresarial

- Consultor de universidades e empresas

- mitlean@osite.com.br

Ubaldo Crepaldi

- Mestrando em Relações Públicas na ECA-USP

- Professor convidado da Aberje - Associação Brasileira de Comunicação Empresarial

- Empresário e consultor associado

- ubaldocrepaldi@terra.com.br 
Resumo

Este artigo discute a decomposição dos objetivos da Comunicação como um processo relacional. Propõe-se, por meio de uma breve revisão da literatura e da apresentação de alguns resultados de investigação, contribuir para a construção de um conceito de organização como processo de comunicação e relacionar as ações de comunicação com sua eficácia na contribuição para a consecução dos objetivos empresariais.

PALAVRAS-CHAVE: COMUNICAÇÃO • CONCEITO - OBJETIVOS • INVERSÕES • RETORNOS

\section{Abstract}

This article discusses the decomposition of the objectives of Communication as a process of relationship. Through one brief revision of the literature and the presentation of some results of inquiries, it aims to contribute to the construction of a concept of Organization as a Communication process and to relate Communication actions to efficaciousness in the contribution to the achievement of the enterprise's objectives.

KEY WORDS: COMMUNICATION • CONCEPT - OBJECTIVES - INVESTMENT - RETURN

\section{Resumen}

Este artículo discute la descomposición de los objetivos de la Comunicación como un proceso de relación. Propone a través de una breve revisión de la literatura y de la presentación de algunos resultados de investigación, contribuir con la construcción de un concepto de Organización como un proceso de Comunicación y relacionar las acciones de Comunicación con eficacia en la contribución para el logro de los objetivos de la empresa.

PALABRAS CLAVES: COMUNICACIÓN • CONCEPTO • OBJETIVOS • INVERSIONES • RETORNOS 


\begin{abstract}
atividade de comunicação constitui um processo complexo e contínuo. Há mais A de sessenta anos, E. K. Strong (1925, p. 9) propôs o conceito AIDA - Atenção, 1 Interesse, Desejo e Ação - para explicar os objetivos da comunicação em relação aos passos que levam a uma decisão de compra. Boone e Kurtz (1998, p. 392) referem-se a esse conceito quando afirmam que uma mensagem, para ser efetiva, deve atender a três requisitos: 1) ganhar a atenção do receptor; 2) ser entendida por ambos, receptor e emissor; 3 ) estimular as necessidades do receptor e sugerir um método apropriado para satisfazê-las. Kotler (1998, p. 532), trabalhando com o modelo da Hierarquia de Efeitos - aprendizagem, percepção e ação -, descreve os seis estados de disposição de compra: consciência; conhecimento; simpatia; preferência; convicção e compra. O comunicador de Marketing, segundo o autor, "precisa saber como mover a audiência-alvo para os estados mais elevados". McCarthy e Perreault (1997, p. 129130) enfatizam a importância da promoção (comunicação) no processo por eles denominado de Processo de Adoção, que contém as seguintes etapas: conscientização; interesse; avaliação; experimentação; decisão e confirmação.
\end{abstract}

Tudo o que já foi dissertado sobre o papel da comunicação no processo de compra e adoção de novos produtos nos ajuda a perceber que devemos incrementar as etapas e que esses conceitos podem ser aplicados em quaisquer instâncias em que a comunicação se faça necessária, ou seja, no âmbito administrativo, mercadológico ou institucional.

Entendemos que quanto mais detalhado o processo, melhor será a definição das ações de comunicação mais apropriadas para fazer frente às etapas previstas propiciando uma análise sistêmica e a integração das diferentes estratégias.

Sistematizando e ampliando o que os vários autores citados propuseram, apresentamos os objetivos que, em nosso entender, compõem o processo da comunicação:

1 - Despertar consciência: as necessidades são inerentes aos seres humanos, conforme discutimos anteriormente. Mas, em muitos casos, algumas delas não estão no nível do sentido ou da percepção. Despertar um certo nível de consciência das necessidades e carências relacionadas com o objeto da comunicação deve ser a primeira etapa do processo de comunicação.

2 - Chamar atenção: um indivíduo, com um certo grau de consciência de suas necessidades e carências, certamente terá sua atenção despertada com maior facilidade. Obviamente, mensagens repletas de elementos criativos, exóticos, engraçados e até 
grotescos tendem a chamar atenção. No entanto, se o receptor não tiver consciência alguma da relevância da mensagem para ele, o processo se extingue na atenção.

3 - Criar interesse: um certo grau de consciência prévia direciona a atenção do indivíduo, despertando interesse. Para isso, é importante que os elementos utilizados na chamada de atenção para a mensagem estejam relacionados ao despertar da consciência.

4 - Proporcionar conhecimento: o receptor interessado está pronto para receber informação mais detalhada para obter e/ ou ampliar seus conhecimentos sobre o objeto da comunicação. Nesta etapa, a mensagem deve ser mais consistente, detalhada e substanciosa para facilitar a compreensão.

5 - Garantir identificação, empatia: as informações devem ser elaboradas e transmitidas levando-se em consideração as características do contexto de percepção, o vocabulário literário e gráfico e o perfil psico-sociodemográfico do receptor para que ele se identifique com o objeto da comunicação, estabelecendo-se, conseqüentemente, uma relação de empatia.

6 - Criar desejo, suscitar expectativa: uma vez que o indivíduo se identifique com as propostas, mensagens e produtos apresentados, há que se adicionar ao processo de comunicação elementos que criem desejo de compra ou suscitem expectativa em relação à efetiva aquisição, posse e uso do bem/ serviço/ idéia/ conceito.

8 - Conseguir a preferência: como a empresa não está sozinha no mercado, o próximo passo do processo de comunicação exige ações para garantir a preferência do indivíduo a despeito das ofertas dos concorrentes. Algumas empresas conseguem levar os receptores até a fase anterior, do desejo ou expectativa, mas não conseguem evitar que os potenciais clientes comprem produtos de seus concorrentes.

9 - Levar à decisão: depois de conseguir a preferência do receptor, a empresa deverá levá-lo a se decidir pela compra ou a realizar aquilo que o objeto da comunicação preconiza.

10- Efetivar a ação: muitas vezes, a tomada de decisão não é seguida de imediato pela ação objetivada pela comunicação. São vários os fatores que podem interferir no prosseguimento da seqüência: ausência de recursos financeiros para consumar a aquisição; falta de tempo para se dirigir ao local de vendas; surgimento de outras prioridades etc. A empresa deve identificá-los e procurar minimizar seus efeitos e/ ou valorizar outros fatores que levem o público-alvo à ação. Trata-se da principal consagração de todo esforço de Marketing, mas não é a única nem a final.

11- Garantir e manter a satisfação pós-ação: os sistemas de atendimento ao cliente (SAC) e os serviços de treinamento e orientação ao cliente são alguns dos aparatos à disposição das empresas para manter uma relação positiva com os compradores mesmo depois da realização da venda. Anúncios e mensagens diretas que elogiam a decisão de compra (ou da ação) e que ratificam o bom gosto e a inteligência da preferência pela marca (ou da realização) geralmente contribuem para a manutenção de um certo nível de satisfação mesmo que o produto em si (ou a ação em si) não o proporcione.

12- Estabelecer interação: as novas tecnologias, principalmente as relacionadas com a Internet, possibilitam às empresas estabelecer um fluxo contínuo, de duas mãos, com seus interlocutores. As reclamações e as sugestões, se bem recebidas e pro- 

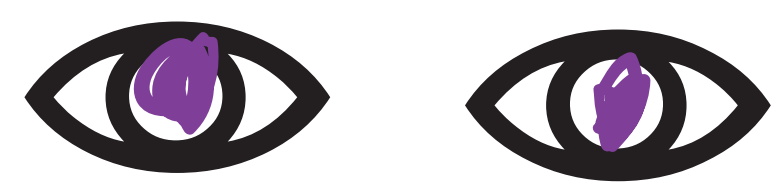

cessadas, podem se transformar em elogios e em desenvolvimento efetivo dos negócios da empresa num processo constante e consistente de melhoria de relações com seus públicos.

13- Obter fidelização: manter o cliente constitui um grande desafio para as empresas. Muitas são as razões que podem levar um comprador de um determinado produto de uma empresa a adquirir mercadoria de outra. A empresa deverá identificar as razões e estudar se é possível revertê-las. Caso seja possível, fazer com que o público saiba disso. Se não for possível, ressaltar outras razões que possam manter o cliente fiel à organização.

14- Gerar disseminação de informações pelos interlocutores: o último estágio pressupõe a formação de agentes geradores e disseminadores de comunicação positiva a partir dos públicos-alvos. A empresa deverá estabelecer estratégias de comunicação específicas para incentivar seus clientes satisfeitos a emitir seus sentimentos e compartilhar suas experiências positivas com outras pessoas que fazem parte de sua rede de relacionamentos. Assim procedendo, a empresa conseguirá ampliar seus canais de comunicação.

Para contribuir para um maior entendimento do processo apresentado, faz-se necessário ressaltar o seguinte:

- A consecução dos objetivos acima listados não é atribuição apenas da atividade de Comunicação. As decisões estratégicas em relação a produtos/ serviços, preço e distribuição são objetos de avaliação e de ação ao longo do processo, juntas ou separadas, presentes ou ausentes em uma ou outra fase, de acordo com as estratégias gerais definidas para se atingir os objetivos de cada etapa. Como definimos a atividade de Comunicação como a ação de "tornar comum" a informação, esta deverá estar presente em todas as fases que compõem o processo, visto que sempre haverá algo a ser compartilhado com os públicos-alvos.

- Nem todos os segmentos-alvo podem estar, simultaneamente, numa mesma etapa. O mesmo ocorre com as pessoas que compõem um dado segmento-alvo. Cabe, portanto, à empresa identificar em que fases se encontram os segmentos e indivíduos mais significativos e estabelecer ações diferenciadas para alcançá-los. Este monitoramento deve ser realizado a partir de pesquisas junto aos públicos-alvos.

- O conhecimento das etapas e o devido monitoramento do processo possibilitam à empresa identificar as ações de comunicação da concorrência e da mídia em geral e seus efeitos nos públicos-alvos. Assim, em vez de estabelecer estratégias visando a todas as fases, ela poderá se concentrar naquelas que lhe forem mais convenientes. Exemplificando: se a mídia em geral despertou a consciência dos públicos-alvos em relação à questão da violência e dos riscos de seqüestros, se os concorrentes já chamaram a atenção passando informações sobre os benefícios da blindagem e despertaram desejo e expectativa em relação ao veículo blindado, caberá a uma dada loja que comercializa esses produtos desenvolver ações que levem o potencial comprador à preferência, à decisão, e assim por diante. 
- Nem todos os produtos demandam a passagem por todas as etapas listadas. As ações de comunicação mercadológica de produtos de conveniência ocorrem geralmente a partir do âmbito das preferências. Produtos de compra comparada normalmente exigem estratégias nas fases de conhecimento, identificação, expectativa etc. No que se refere aos produtos de compra complexa (bens e serviços de especialidade), todas as etapas do processo deverão ser observadas. Mas é preciso ressaltar que ações eficazes nas fases que se seguem à criação de desejo e expectativa são fundamentais para garantir o sucesso de qualquer produto.

- A disseminação das ações de comunicação em todas as etapas não é atribuição de um canal ou de uma ferramenta. Todos os canais e ferramentas pertinentes e disponíveis às empresas desempenham funções importantes e integradas na consecução dos objetivos citados em cada fase do processo. Sem a pretensão de generalizar ou de normatizar, podemos dizer que a Propaganda tende a ser mais acionada nas fases iniciais: consciência, atenção, interesse, conhecimento, identificação, Desejos. Press releases com informações sobre a empresa e seus produtos cujo objetivo seja o de gerar mídia espontânea geralmente ajudam na disseminação do conhecimento, na criação de expectativas e na afirmação de preferências. Outras atividades de Relações Públicas são importantes para o estabelecimento de identificação com os diferentes públicos, além de colaborar decisivamente nas etapas relacionadas com satisfação, interação, fidelização e disseminação. As ferramentas de merchandising e de promoção de vendas, por sua vez, prestam-se efetivamente para levar o cliente potencial à decisão e à ação.

- A seqüência sugerida pode ser utilizada para a fixação dos atributos intangíveis de um produto. Caso uma indústria de moagem de café queira relacionar seu produto com o atributo intangível "tradição", deverá: despertar junto ao seu público-alvo consciência de que tradição em fabricação de café é importante, chamar atenção e criar interesse, fornecer informações da história e do processo de fabricação do produto que o relacionem com tradição, e assim por diante.

- Cabe ao profissional da comunicação não privilegiar ferramenta alguma em detrimento de outras, elaborando estratégias integradas, coerentes com uma orientação sistêmica e que propiciem sinergias entre os vários esforços.

- As etapas que comportam os objetivos acima expostos não se referem apenas à comunicação mercadológica, mas também à comunicação administrativa e à institucional, como veremos nos exemplos apresentados a seguir.

\section{Exemplos da aplicação}

\section{Na comunicação administrativa}

Uma empresa preocupada com o alto índice de absenteísmo resultante de licença médica decide realizar um trabalho para posicioná-lo em um patamar aceitável. 
- Consciência: publicação de artigos sobre cuidados em relação à saúde nos veículos internos (cartazes, jornais, boletins etc.).

- Atenção/ interesse/ conhecimento: nos encontros da CIPA (Comissão Interna de Prevenção de Acidentes) ou nas reuniões departamentais, distribuir materiais mais elucidativos, com indicações práticas de cuidados físicos.

- Identificação/ expectativa/ preferência: propiciar sessões internas de avaliação física; criar locais internos onde os funcionários possam relaxar e/ ou praticar exercícios físicos; investir na melhoria das condições de trabalho; destacar todas as medidas utilizando os meios disponíveis e mais pertinentes.

- Decisão/ ação: estabelecer um programa de premiação aos funcionários com os menores índices de absenteísmo e divulgá-lo insistentemente.

- Satisfação/ interação/ disseminação: destacar os funcionários que mais se empenharam no programa; apresentando seus depoimentos nas publicações internas; enviar mensagens elogiosas aos familiares dos que mais se destacaram.

\section{Na comunicação institucional}

Uma indústria multinacional que opera no setor automobilístico, localizada em uma cidade interiorana, deseja melhorar suas relações com a comunidade local.

- Consciência: disseminar por meio da mídia espontânea local informações sobre a importância do setor automobilístico para a economia do país, da região e da cidade.

- Atenção/ interesse: cuidar da aparência das instalações, tanto internas quanto externas, para que elas se diferenciem das demais indústrias locais.

- Conhecimento / identificação: elaborar e distribuir, à opinião pública local, material impresso informativo sobre as atividades da indústria, as razões da escolha do local para a operação, a criação de empregos, a contribuição para o incremento da arrecadação de tributos da cidade etc. Esses materiais impressos podem ser disponibilizados nas igrejas, nas grandes lojas, nos sindicatos rurais e comerciais, na prefeitura, nos clubes, entre outros.

- Expectativa/ preferência: manter a população informada sobre a situação da indústria, as perspectivas de crescimento, as exportações, enfim, manter uma "agenda positiva" com os líderes de opinião. Isso pode ser realizado por meio de palestras, mini-seminários etc.

- Decisão / ação: proporcionar à população oportunidades de visita às instalações, promover almoços e cafés da manhã para os líderes comunitários, oferecer cursos de capacitação profissional à população em geral, contratar pessoas portadoras de deficiência etc.

- Satisfação/ interação/fidelização/ disseminação: manter canais abertos de comunicação com a população por meio de sites de relacionamento, tele-atendimento, visitas; patrocínio constante dos eventos esportivos, culturais e sociais mais importantes da região; doar veículos para a prefeitura local utilizá-los para o bem público, fiscalizando e garantindo seu bom uso; publicação de relatórios sociais anuais, 
enfatizando sempre os fatores de identificação, de convergência e de cumplicidade presentes na relação da indústria com a cidade etc.

\section{Avaliação da comunicação interna}

Para possibilitar um melhor monitoramento das estratégias de Comunicação Integrada, propomos a realização de uma análise constante das diferentes habilitações de Comunicação Organizacional e sua efetividade no atendimento dos objetivos e metas definidos em cada fase no processo geral.

Desta forma, é possível avaliar a Comunicação em função de um modelo de resposta comportamental, destacando as diferentes ações e sua capacidade de gerar respostas positivas e/ ou negativas em cada etapa.

Esta avaliação propicia correções nas ações futuras de propaganda, promoção de vendas/ merchandising e Relações Públicas/ assessoria de imprensa.

GERA A CONSCIÊNCIA
CHAMA A ATENÇÃO
DESPERTA O INTERESSE
PASSA INFORMAÇÃO
GERA EMPATIA/ IDENTIFIC.
CRIA DESEJO / EXPECTATIVA
CRIA A PREFERÊNCIA
INCENTIVA A DECISÃO
PROVOCA A AÇÃO
GERA SATISFAÇÃO
GERA A INTERAÇÃO
INCENTIVA A FIDELIZAÇÃO
PROVOCA O BOCA-A-BOCA

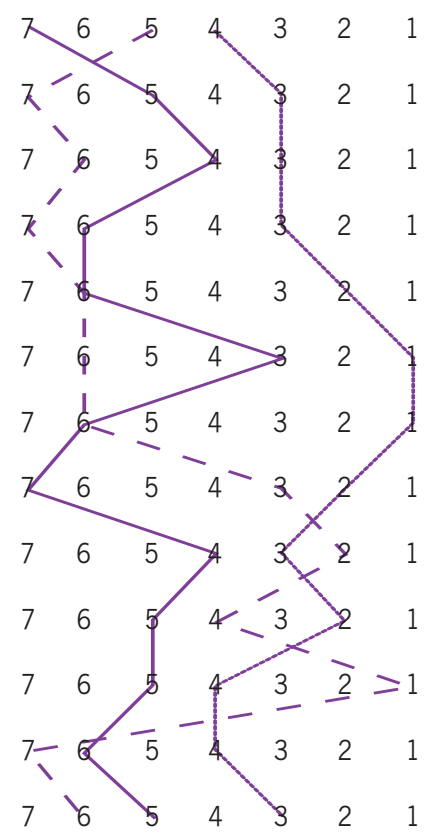

NÃO GERA A CONSCIÊNCIA

NÃO CHAMA A ATENÇÃO

NÃO DESPERTA O INTERESSE

NÃO PASSA INFORMAÇÃO

NÃO GERA EMPATIA/ IDENTIFIC.

NÃO CRIA DESEJO/ EXPECTATIVA

NÃO CRIA A PREFERÊNCIA

NÃO INCENTIVA A DECISÃO

NÃO PROVOCA A AÇÃO

NÃO GERA SATISFAÇÃO

NÃO GERA A INTERAÇÃO

NÃO INCENTIVA A FIDELIZAÇÃO

NÃO PROVOCA O BOCA-A-BOCA

Propaganda

- - Promoção de vendas

Assessoria de imprensa

Modelo de Avaliação proposto por José Carlos Barros, Mitsuru Yanaze e Kleber Markus, 2000. 


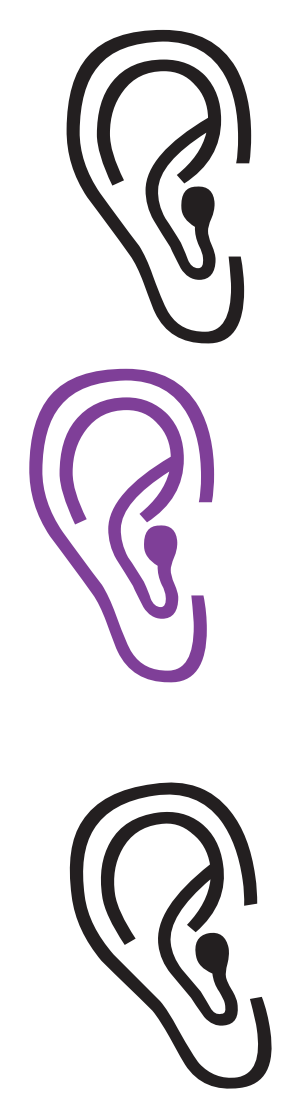

\section{Avaliação da eficácia na Comunicação}

A organização como um processo de construção permanente se confunde com o próprio composto da Comunicação, vista no seu sentido mais amplo (Taylor, 1993).

Desta forma, é lícito esperar que toda Comunicação reflita, positiva ou negativamente, direta ou indiretamente, no resultado econômico e na evolução patrimonial da organização, caso contrário a ação é estranha à mesma.

Senão, vejamos:

- toda comunicação tem objetivos;

- todos os objetivos podem ser decompostos em metas quantificáveis, o que não significa expressas somente em valores monetários;

- todas as metas quantificadas podem direta ou indiretamente ser traduzidas em valores monetários e comparadas aos recursos necessários para a sua consecução (Taxa de Retorno do Investimento);

- O prazo necessário para atingir as metas (Período do Retorno do Investimento) depende da complexidade e da abrangência da ação pensada.

Assim sendo, os objetivos da Comunicação expostos podem ser agrupados segundo as usuais técnicas de análise do impacto no resultado econômico e, conseqüentemente, no patrimônio da organização. 
Dentre as treze fases do processo da Comunicação, as cinco primeiras (consciência, atenção, interesse, informação e identificação / empatia), normalmente alvos de ações de branding, tendem a ser mensuradas por pesquisas de imagem. Contudo, sempre há indicadores de performance, como, por exemplo: a diferença, positiva ou negativa, entre o valor patrimonial das ações e o seu valor de mercado; os percentuais de interesse, o grau de conhecimento e de empatia anteriores comparados com os obtidos após a ação comunicacional. Através da formação de séries históricas, algumas empresas já conseguem relacionar tais indicadores com os resultados econômicos, aferindo, desta forma, a eficácia dos investimentos na consecução desses objetivos.

Por exemplo, uma empresa que mantenha uma série histórica de pesquisas sobre sua imagem descobrirá, ao longo do tempo, uma relação entre os seus índices de admiração e a proporção entre os valores patrimoniais e de mercado de suas ações.

Da mesma forma, embora tendo que isolar outros fatores, também é possível descobrir relações entre imagem e nível de faturamento bruto por região, clima organizacional e taxa de absenteísmo com níveis de "orgulho da marca" e de produtividade etc.

As metas (quantificáveis, portanto) relacionadas com os quatro objetivos subseqüentes - expectativa, preferência, decisão e ação - normalmente produzem impacto quase que diretamente no resultado econômico, sendo normalmente passíveis de Análise de Retorno do Investimento através de técnicas próprias (Gitman, 2001, p. 204). As ações de Comunicação voltadas para estes objetivos são as de mais fácil relacionamento com os resultados.

Por fim, relacionadas aos quatro últimos objetivos - satisfação, interação, fidelização e disseminação -, se enquadram um grande número de ações de Comunicação que visam à sustentabilidade das operações da organização e que podem ser quantificadas e comparadas com desempenhos anteriores, bem como com os resultados econômicos então obtidos.

Por exemplo, em uma instituição de ensino, as rematrículas (contrapartida da evasão escolar) estão diretamente relacionadas com a rentabilidade do período. Postos de combustíveis que mantêm controle sobre a habitualidade dos consumidores descobrem uma relação direta entre a mesma e o seu resultado econômico.

Desta forma, é lícito afirmar que toda e qualquer Comunicação influi no resultado econômico e esta influência pode ser mensurada com precisão crescente. 


\section{Bibliografia}

BOONE, L. e KURTZ, D. Marketing contemporâneo. Rio de Janeiro: LTC, 1998.

GITMAN, L. J. Princípios de administração financeira essencial. 2a ed. Porto Alegre: Bookman, 2001.

KOTLER, P. Administração de marketing: análise, implementação... São Paulo: Atlas, 2001.

Administração de marketing. São Paulo: Atlas, 1998.

KUNSCH, M. M. K. Obtendo resultados com Relações Públicas. São Paulo: Pioneira, 1997.

Planejamento de Relações Públicas na comunicação integrada. São Paulo: Summus, 2003.

McCARTHY, J. e PERRAULT JR., W. D. Marketing essencial. São Paulo: Atlas,1997.

STRONG, E. K. The Psychology of Selling. New York: McGraw-Hill, 1925.

TAYLOR, J. R. Rethinking the Theory of Organizational Communication: How to Read an Organization. Norwood: Ablex, 1993.

YANAZE, M.; BARROS, J. C. de e MARKUS, K. Avaliação da comunicação integrada. São Paulo: Consultoria, 2000.

YANAZE, M. Marketing e comunicação: conceitos e aplicações. Tese de Livre-Docência, São Paulo: ECA-USP, 2004.

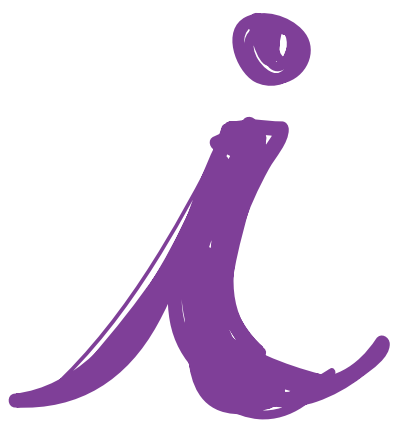

